\title{
HISTOPATOLOGIA DAS TERMINAÇÕES NERVOSAS NA LARINGITE TUBERCULOSA
}

\author{
José Fernandez *
}

Desde que em 1879 Joffroy ${ }^{29}$ descreveu lesões histológicas de polineurite em um tuberculoso, a bibliografia sôbre tal processo tem aumentado sem contudo chegar a ser copiosa. Apesar da importância do problema, não se lhe tem dado a atenção que merece; não se justifica considerar como pràticamente despidas de importância as lesões nervosas, de sintomatologia imprecisa, que aparecem na tuberculose como complicação terminal, principalmente depois dos trabalhos de Speransky ${ }^{41}$, Sturm ${ }^{48,49}$ e Rosenthal $36,37,38,39$.

Em 1932 Filatowa e Lawrentjew 18 publicaram o primeiro trabalho sôbre as alterações nervosas na laringite tuberculosa, baseando-se em 3 casos nos quais estudaram, além das lesões do nervo laríngeo superior, as alterações do vago e do gânglio plexiforme; em todos os casos descreveram modificações características, principalmente formações nodulares ou engrossamentos no trajeto das fibras nervosas e excrescências laterais; chamaram a atenção para o fato de que, nos processos exsudativos, as alterações são, geralmente, mais intensas e que, quando a úlcera laríngea é unilateral, as fibras nervosas homolaterais apresentam alteraçōes mais intensas. Em 1934 Lawrentjew e Filatowa ${ }^{31}$ voltaram a estudar as alterações das fibras nervosas na laringite tuberculosa, particularmente as terminações do nervo laríngeo inferior, mostrando que as terminações são as primeiras a se alterarem, apresentando formaçōes em bolas argênticas (neuroma das terminações) e que nas fibras nervosas ocorrem alterações irritativas (proliferativas) e degenerativas. Em 1951 Guillén ${ }^{20}$ estudou as lesões nervosas na laringite tuberculosa, assinalando alterações das neurofibrilas e a presença de engrossamentos e estrangulamentos alternados que dão à fibra aspecto arrosariado característico; as placas motoras apresentavam colaterais neoformadas que por vêzes perfuram o sarcolema para se colocarem entre o conjuntivo miofibrilar, apresentando bolas argênticas semelhantes às descritas por Lawrentjew e Filatowa. Jabonero ${ }^{25}$, em 1952, estudou as alterações dos aparelhos sensitivos da musculatura lisa de traquéias e brônquios humanos na tuberculose; tais alterações são do mesmo tipo porém de menor intensidade que as descritas por Lawrentjew e Filatowa (graves alterações

* Professor de Citologia e de Histologia da Faculdade Católica de Filosofia; Assistente de Histologia da Fac. Med. da Univ. da Bahia; Patologista do Manicômio Juliano Moreira e da Fundação Hospitalar Octavio Mangabeira. 
das placas motoras da laringe, assim como algumas das terminações sensitivas subepiteliais). Recentemente Jabonero ${ }^{27}$ voltou a estudar a inervação da laringe em casos normais, de tuberculose e de câncer, detendo-se particularmente nas alterações dos nervos sensitivos da mucosa, das placas motoras e das formações vegetativas distais.

\section{MATERIAL, MÉTODOS E RESULTADOS}

Examinamos 16 laringes de pacientes que faleceram de tuberculose pulmonar grave, cuja idade variava entre 15 e 68 anos; 10 pacientes eram do sexo masculino, 6 do feminino (quadro 1). As lesões correspondiam a vários tipos, indo desde a simples infiltração até a caseificação extensa. Como contrôle, estudamos a inervação de 4 laringes histologicamente normais.

De cada peça foram tirados 4 fragmentos, sendo as impregnações feitas com o método de Boeke e, eventualmente, com o nitrato de prata reduzido de Cajal. Os cortes de cada bloco foram divididos em 4 grupos: no primeiro os cortes foram montados sem sofrerem outro processo; no segundo foi feita a viragem em ouro pelo método de Castro ${ }^{8}$; no terceiro, viragem em ouro e coloração de fundo pela hematoxilina-eosina; no quarto, viragem e coloração pelo tricrômico de Gomori. Também foram feitos cortes em parafina, corados pela hematoxilina-eosina e pelo Gomori.

Em laringes normais observamos, na zona situada entre a cartilagem e o epitélio de revestimento, finos fascículos de fibras nervosas, em sua grande maioria mielínicas; estas fibras formam plexos que se dirigem para a periferia e, nas proximidades do epitélio, perdem o revestimento mielínico, emitindo pequenas colaterais tortuosas que se terminam por formaçōes em anéis, ponta de lança ou massas. Além destas formaçōes existem colaterás formadas, quase que exclusivamente, por neurofibrilas que, em determinado ponto, se encontram para formarem, duas ou três delas, pequeno enovelado, posslvelmente de caráter sensitivo. Entre as células epiteliais podemos notar pequenas e delicadas ramificações somente visíveis nos cortes intensamente impregnados. Em uma vista de conjunto podemos distinguir dois plexos; um profundo e outro superficial. A mucosa, particularmente a que reveste a aritenóide, é rica em nervos, com ramificaçōes numerosas terminando-se em pequenas bolas argênticas. Ao nivel da epiglote, na região subepitelial, as fibras nervosas perdem o revestimento mielínico, dividem-se em dois ramos que, por sua vez, vão se dividindo por ãicotomia até terminarem em formações ovalares fortemente impregnadas ou, formam, no bordo livre da epiglote, figura enovelada semelhante aos corpúsculos sensitivos de Dogiel. As glândulas apresentam inervação própria, constituídas por fibras finas e bem impregnadas que percorrem a preparação entre um e outro ácino, envolvendo-os sob forma de delicado plexo apôsto à superfície do ácino, ou penetrando nêles e aí dividindo-se em delicadas fibrilas que seguem e contornam os limites entre uma e outra célula e, por vêzes, dividindo-se em 4 a 6 delicados filetes que terminam livremente por diminutas formações em bolas, anéis ou fibrilas delicadas e mais impregnadas que os filetes.

As placas motoras, em essência, não diferem das observadas em outras partes do organismo. A fibra nervosa perfura o sarcolema e se estreita, dividindo-se em pequenos ramos que terminam livremente sôbre os núcleos dos lemnócitos; a êste nivel a estriação se torna mais apagada e depois desaparece sem zona limitante. Na região em que o axônio entra em contacto com a miofibrila, observa-se uma zona clara com granulações finas fortemente impregnadas e alguns núcleos. Vez por outra nota-se que as ramificaçōes do axônio ultrapassam a zona granulosa acompanhando-se de uns poucos núcleos; outras vêzes as terminações apresentam estrutura fibrilar em retículo rudimentar que lembra o espongioplasma. Os núcleos diferem quanto à morfologia e quanto à posição: uns, mais numerosos, correspondem ao sarcoplasma, à própria fibra muscular, nada diferindo dos observados em 


\begin{tabular}{|c|c|c|c|c|}
\hline Casos & Registro & Sexo & Idade & Tipo de lesão pulmonar \\
\hline $1^{*}$ & 2054 & $\mathbf{M}$ & 35 & Ulcero-caseosa à direita. \\
\hline $2 *$ & 1703 & $\mathbf{F}$ & 15 & Ulcero-cáseo-nodular bilateral. \\
\hline $3^{*}$ & 1611 & $\mathbf{M}$ & 36 & Ulcerosa bilateral. \\
\hline 4 & 1050 & M & 42 & $\begin{array}{l}\text { Ulcerosa extensa à esquerda com dissemina- } \\
\text { ção micronodular à direita. }\end{array}$ \\
\hline $5 *$ & 1315 & $\mathbf{M}$ & 68 & Ulcero-cáseo-nodular bilateral. \\
\hline 6 & 991 & $\mathbf{F}$ & 32 & Ulcero-fibrosa bilateral. \\
\hline $7^{*}$ & 1364 & $\mathbf{M}$ & 64 & Olcero-fibrosa bilateral. \\
\hline $8^{*}$ & 1632 & $\mathbf{M}$ & 21 & Olcero-caseosa bilateral. \\
\hline 9 & 203 & $\mathbf{F}$ & 26 & Ülcero-fibro-caseosa bilateral. \\
\hline $10^{*}$ & 1555 & M & 25 & Ulcero-caseosa bilateral. \\
\hline 11 & 1531 & $\mathbf{F}$ & 21 & Ulcero-fibro-caseosa bilateral. \\
\hline 12 & 1023 & $\mathbf{M}$ & 36 & Ulcero-caseosa bilateral. \\
\hline $13^{*}$ & 1576 & $\mathbf{M}$ & $\mathbf{3 4}$ & Olcero-caseosa bilateral. \\
\hline 14 & 1280 & $\mathbf{M}$ & 31 & Ülcero-caseosa bilateral. \\
\hline $15^{*}$ & 1481 & $\mathbf{F}$ & 18 & $\begin{array}{l}\text { Úlcero-fibro-caseosa à direita, com dissemina- } \\
\text { ção para o pulmão esquerdo. }\end{array}$ \\
\hline $16^{*}$ & 1491 & $\mathbf{F}$ & 24 & Elcero-caseosa bilateral. \\
\hline
\end{tabular}

Quadro 1 - Dados gerais dos 16 casos de tuberculose estudados. * Pacientes falecidos com menos de 30 dias de hospitalização.

\begin{tabular}{|c|c|c|c|c|c|c|}
\hline \multirow{2}{*}{ Casos } & \multicolumn{2}{|c|}{ Lesões macroscópicas } & \multicolumn{4}{|c|}{ Lesões microscópicas } \\
\hline & Infiltração & Ulceração & Infiltrativa & Nodular & Caseosa & Pericondrite \\
\hline 1 & + & + & + & - & - & + \\
\hline 2 & + & - & + & - & - & + \\
\hline 3 & + & + & + & + & - & - \\
\hline 4 & + & - & 一 & + & - & - \\
\hline 5 & + & + & - & - & + & 一 \\
\hline 6 & + & - & + & 一 & 一 & - \\
\hline 7 & - & + & + & + & - & + \\
\hline 8 & + & + & 一 & - & + & 一 \\
\hline 9 & + & + & - & + & + & - \\
\hline 10 & + & + & - & - & + & - \\
\hline 11 & 一 & + & - & + & + & - \\
\hline 12 & + & - & + & - & - & + \\
\hline 13 & + & + & + & - & - & - \\
\hline 14 & + & - & + & + & - & - \\
\hline 15 & + & + & - & - & + & - \\
\hline 16 & + & + & - & - & + & - \\
\hline
\end{tabular}


outros pontos da fibra muscular (núcleos fundamentais); outros, em menor número (núcleos de arborização), se apõem às ramificações do axônio; outros têm situação mais superficial e entram em contacto com a união da bainha de Henle e o sarcoplasma (núcleos da bainha). Podemos observar, em uma placa motora, a fibra medulada perfeitamente impregnada e volumosa e uma fibrila amedulada muito delicada que segue paralelamente a fibra precedente e penetra com ela no sarcoplasma, terminando, dentro da placa motora, mediante pequenissima e rudimentar arborização.

Menos freqüentes que as placas motoras, porém $n^{8}$ tidamente impregnadas, são as formações que terminam em retículo descritas por Boeke como "retículo préterminal" (fig. 1). A fibra nervosa, ao atravessar o sarcolema, se estreita, perde a bainha de mielina e se divide profusamente em fibrilas flexuosas que possuem varicosidades unidas entre si por delicados filamentos. A arborização é muito maior que a observada nas placas motoras clássicas e das varicosidades reticulares parecem partir delicados filamentos. As fibrilas dêste reticulo podem ser divididas em duas espécies: umas mais grosseiras, vigorosamente impregnadas; outras mais delicadas, filiformes, menos impregnadas, que se estendem por um território bem maior que as precedentes. As estriações transversais da fibra muscular não desaparecem se bem possam ficar um pouco mais pálidas.

Foram observadas outras formacões constituidas por fibrilas nervosas bem impregnadas situadas entre feixes musculares estriados; nas proximidades de um feixe muscular de estrutura mais compacta, observamos que as fibras se dividiam em ramos mais delicados formando um conjunto de fibrilas dispostas paralelamente à fibra muscular (fig. 2). O número de fibrilas é variável, como variável é seu diâmetro e a sua impregnação. Ao tempo em que a fibra nervosa se dirige para o músculo, sofre um estreitamento, perde a bainha de mielina e se dispõe em espiral em tôrno de uma ou mais fibras musculares. Este aspecto é bem evidente nas preparações em que a coloração de fundo é feita pela hematoxilina-eosina: as espirais formadas pela fibra nervosa são mais densas na região central que nas laterais; as fibrilas nervosas que integram estas formações se terminam geralmente por expansões claviformes ou discoidais. Estas formaçōes são, ao que tudo indica, sensitivas (fig. 3). Outras vêzes a fibra nervosa se divide em vários filetes, todos perfeitamente impregnados, em forma de rêde de malhas largas; alguns dêstes filetes apresentam pequenos nódulos, outros possuem estrutura fibrilar (fig. 4).

Macroscopicamente, nas laringes patológicas as lesões às vêzes eram tão diminutas que passariam despercebidas não fôsse um exame mais acurado: pequenas granulaçōes algumas vêzes circunscritas, outras confluentes; as confluências são mais freqüentes ao nivel da epiglote ou das faixas ventriculares. Outras vêzes a lesão era maciça, comprometendo grande parte da mucosa que se encontrava espessada, apresentando certa tendência para a invasão das cordas vocais e da epiglote, com aspecto de intensa infiltração serosa. Dividimos as lesões observadas macroscopicamente em infiltrativas e ulcerosas (quadro 2).

Nas preparações coradas pela hematoxilina-eosina e pelo Gomori, as alteraçōes microscópicas apresentam polimorfismo acentuado. As lesões iniciais são constituídas por infiltração difusa, no cório, ou acúmulos de elementos celulares caracteristicos dos processos inflamatórios, com a presença de células epitelióides e, às vêzes, gigantócitos. Os primeiros tubérculos se desenvolvem no tecido subepitelial, entre as glândulas mucosas. Inicialmente o revestimento mucoso que recobre o tubérculo se apresenta indene; entretanto, com a infiltração de células redondas no tecido submucoso, ocorre proliferação da mucosa, com aumento da camada epiteliar pavimentosa e substituição do epitélio cilíndrico por pavimentoso que se estende para a profundidade. $O$ aspecto microscópico permite dividir o quadro histológico. em quatro tipos: infiltrativo, nodular, caseoso e pericondrite. $O$ tipo infiltrativo é constituído por tubérculos epitelióides centrados ou não por gigantócitos, com ou sem caseose, com infiltração de pequenas células redondas e imbebição edematosa dos tecidos circunvizinhos, localizando-se, de preferência, nas cordas vocais, na parede posterior da laringe e na epiglote; a mucosa que recobre esta zona está, ge- 


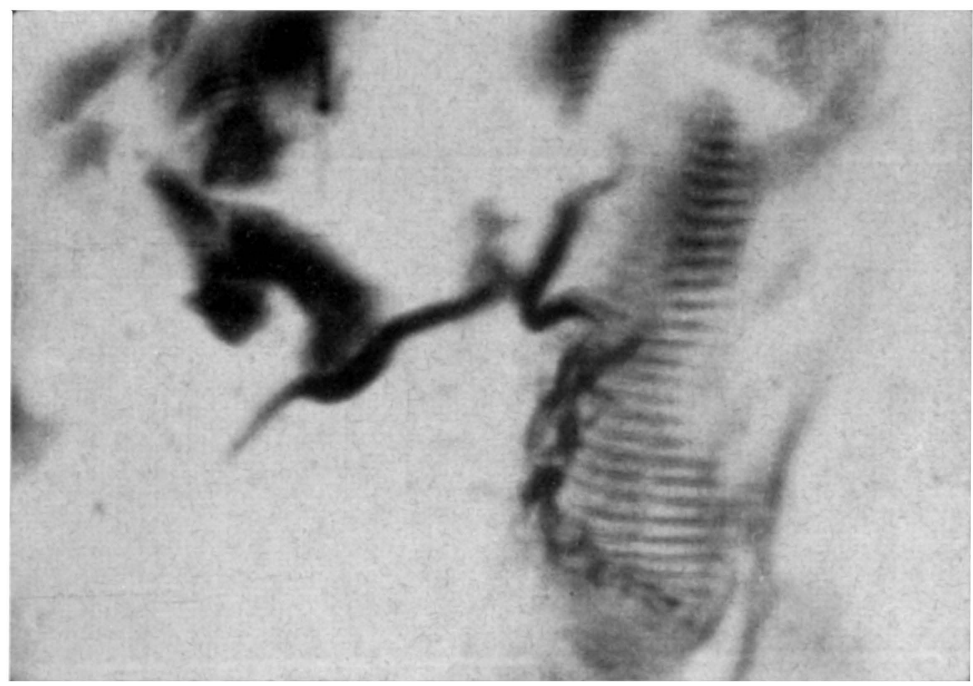

Fig. 1 - Método de Boeke $(450 \times)$ : reticulo pré-terminal de Boeke.

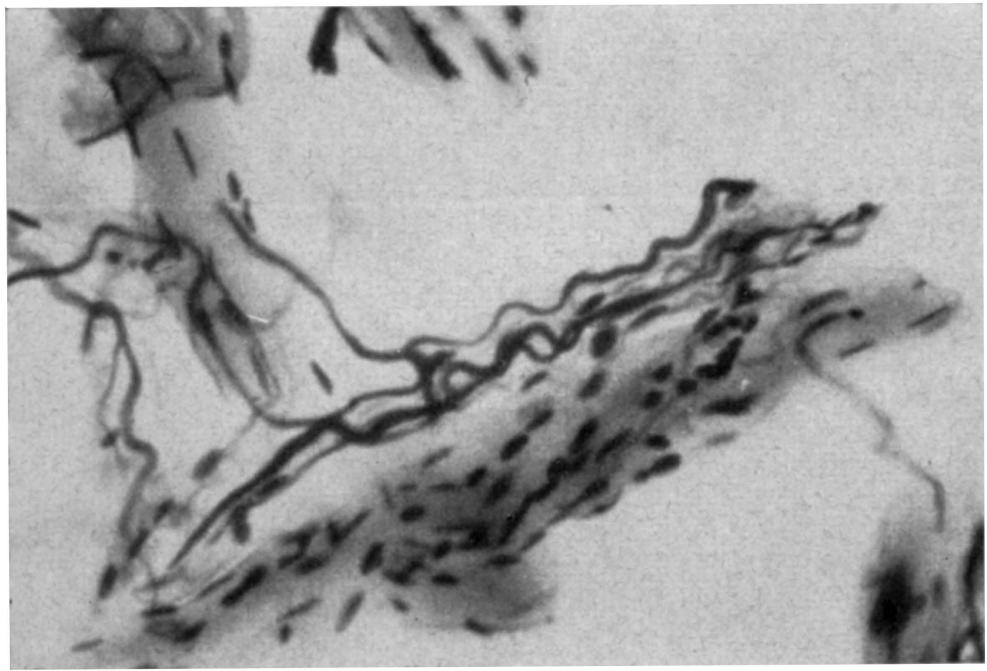

Fig 2 - Método de Boeke (450): fibra nervosa que se divide em ramos delicados formando um conjunto de fibrilas paralelamente $\grave{a}$ fibra muscular. 




Fig. 3 - Método de Boeke (450×): fibra nervosa que se aproxima da muscular envolvendo-a.

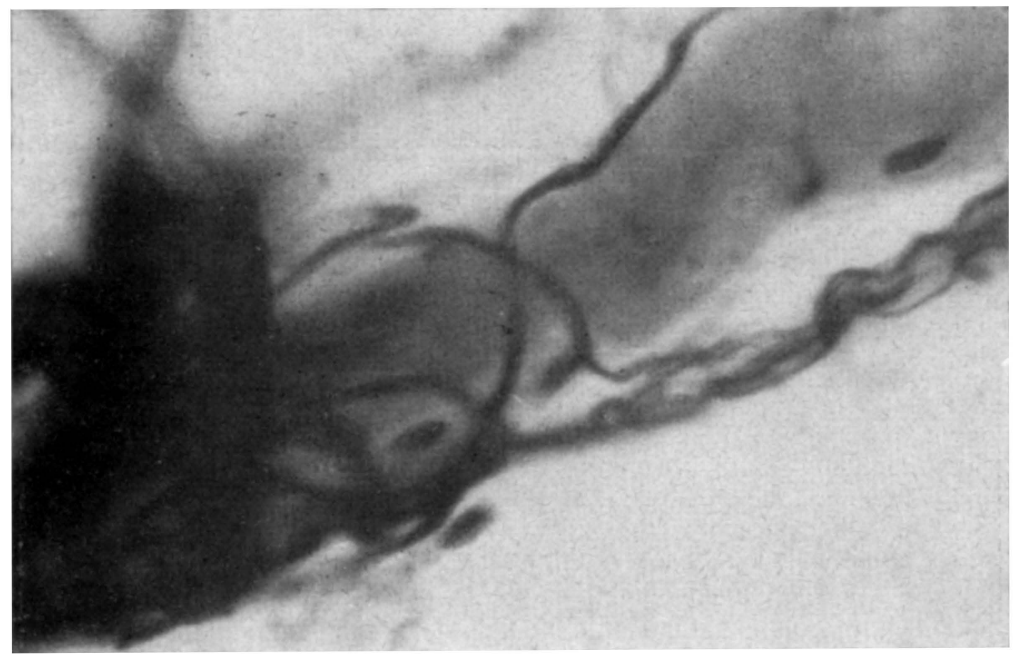

Fig. 4 - Método de Boeke $(450 \times)$ : filetes nervosos que envolvem a fibra muscular em forma de rêde. 
ralmente, indene; a infiltração celular, quando discreta, localiza-se entre o epitélio e o ácino glandular, sendo constituida por linfócitos, monócitos, plasmócitos, células epitelióides e raros gigantócitos. Os processos secundários de caseificação progressiva e de involução, por induração do infiltrado que, em sua evolução morfológica, corresponde ao observado nos focos pulmonares, dependem da tendência da afeç̧ão tuberculosa. A pericondrite se desenvolve pela propagação do processo para a profundidade, sendo mais freqüente na epiglote e nas aritenóides, destruindo o pericondrio, podendo necrosar lentamente a cartilagem.

Nas laringes patológicas as fibras nervosas apresentam-se hipertrofiadas e com nodosidades alternadas com estreitamentos, com aspecto arrosariado. Nas preparações em que a coloração de fundo é feita com a hematoxilina-eosina, podemos notar que êste aspecto aparece, de forma constante, nas proximidades de zonas caseificadas ou em regiōes em vias de caseificaçāo. As nodosidades apresentam aspecto regular e fusiforme, impregnando-se fortemente pela prata. As vêzes a impregnação não se faz uniformemente, corando-se sòmente a zona central; observamos, então, a fibra nervosa como um cordão intensamente impregnado que apresenta formações fusiformes ou esferóides mais claras dispostas com certa regularidade ao longo da fibra nervosa. Em muitas preparaçōes podemos observar fibras nervosas fortemente impregnadas, de trajeto mais ou menos retilíneo, de diâmetro quase constante, situadas em áreas histologicamente patológicas, onde é possivel a verificação de pequenas células redondas, monócitos, histiócitos, algum que outro eosinófilo e vasos fortemente dilatados (fig. 5). Outras vêzes fibras de aspecto semelhante se situam em regiões não muito distantes de folículos de Schuppel-Koster. Foi possivel observar, quando a incidência do corte permitia visualizar a fibra por um longo percurso, que trechos aparentemente normais podem estar situados entre trechos patológicos. Ainda em zonas de infiltração observamos fibras que apresentam pequenas espiculas que lhes emprestam aspecto denteado; vez por outra estas pequenas espículas dão origem a delicadas fibrilas que envolvem ou não as fibras que lhes dão origem, terminando-se, na maioria das vêzes, por volumosas e homogêneas bolas argênticas.

Bastante interessante é a presença de fibras volumosas, de trajeto tortuoso, Intensamente impregnadas, nas quais não é possível a visualização de estrutura alguma, apresentando brotamentos bem impregnados, alguns de volume considerável, terminando, às vêzes, por engrossamentos. Outras vêzes observamos que fibras hipertrofiadas apresentam perda parcial de afinidade pela prata, evidenciando que a apetência destas pelo metal não é uniforme no material estudado (fig. 6). As vêzes, no mesmo corte e na mesma fibra, aparecem tonalidades diversas de impregnaçāo. Em algumas preparaçōes observamos fibras volumosas, porém de impregnação pálida, mais ou menos uniforme, com uma ou outra nodosidade; a parte central do axônio se impregna palidamente, ficando a zona periférica de coloração bem acentuada. Em um periodo mais adiantado de alteração, o axônio vai tomando tonalidade mais carregada, a periferia vai-se tornando mais dèbilmente impregnada, até que a fibra adquira um aspecto edemaclado, dissolvendo-se as envolturas, predominando as células de Schwann que se hipertrofiam. Outras vêzes o cilindro-eixo apresenta vacúolos que aumentam paulatinamente terminando por fragmentar a fibra.

As alterações observadas na placa motora são características. Notamos, como lesão inicial, que a placa motora apresenta finissimas ramlficaçōes. $\mathbf{A}$ medida que progride a alteração, as ramificações vão tomando corpo, primeiro alongando-se, depois dobrando-se sôbre si mesmas, hipertrofiando-se, para, finalmente, perfurar o sarcolema, alojando-se no conjuntivo interfascicular, aparecendo e crescendo uma formaçāo argêntica terminal que chega a ter, às vêzes, dimensões consideráveis. Nas preparações contrastadas pelo Gomori observamos graves alterações: a fibrila nervosa terminal, bem impregnada pela prata, se fragmenta; aparecem formacoóes em bolas argênticas não muito bem conformadas, fragmentadas, desligadas da terminação nervosa, aparece um pigmento que se cora em róseo pálido pelo Gomori. Outras vêzes as alterações iniciais são constituídas por hipertrofia da placa motora 


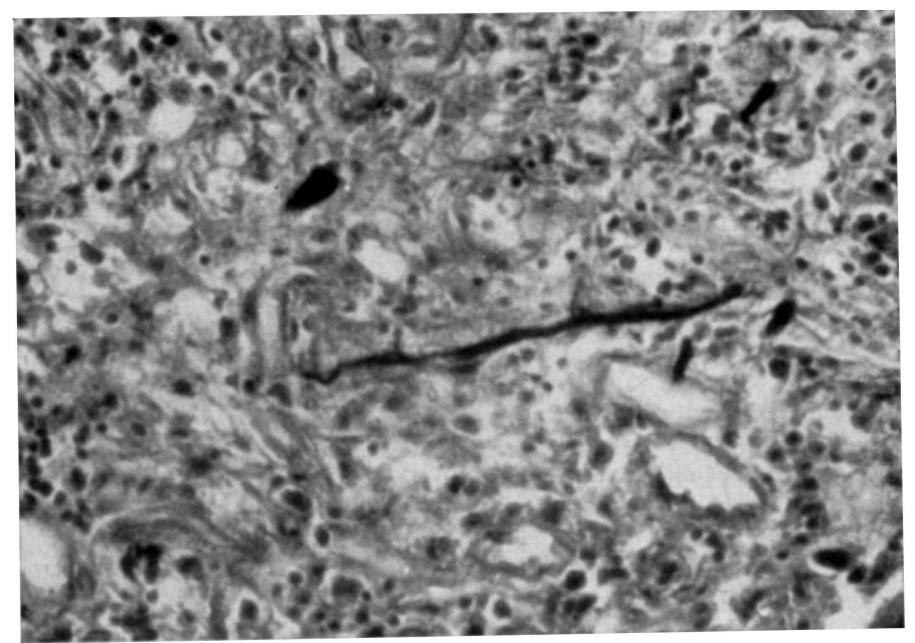

Fig. 5 - Método de Boeke e coloração de fundo pela hematoxilina-eosina $(100 \times)$ : fibra nervosa patológica, de trajeto retilineo, fortemente impregnada, em área infiltrada por linfócitos, histiócitos e eosinófilos, com dilatação vascular e marginaçāo c'e leu乞ósitos.

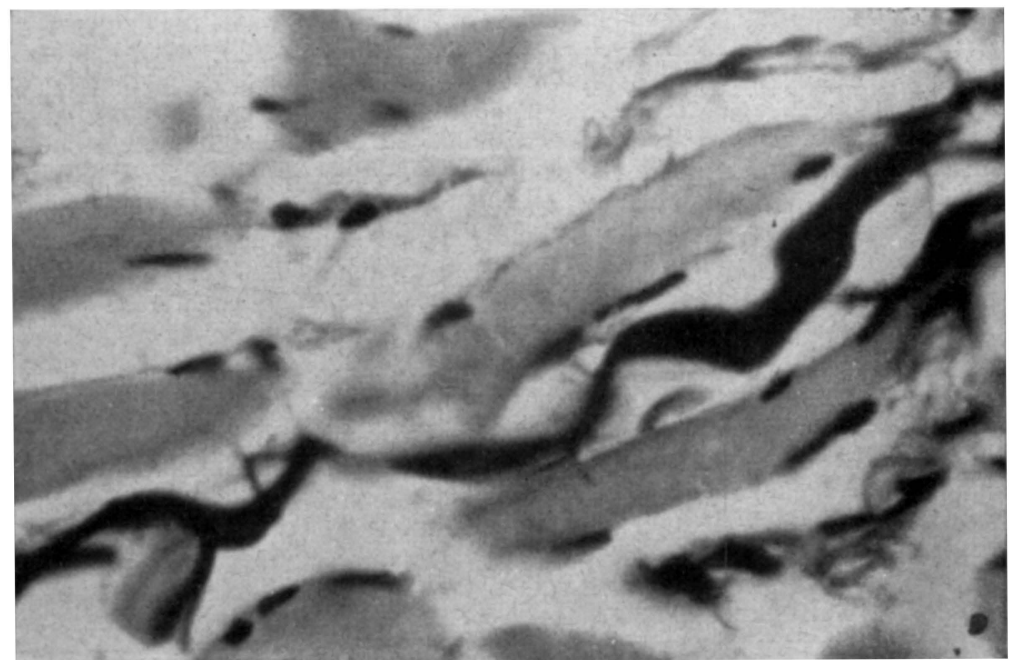

Fig. 6 - Método de Boeke (450)): fibra hipertrofiada, com engrossamentos, apresentando perda parcial da afinidade pela prata. 


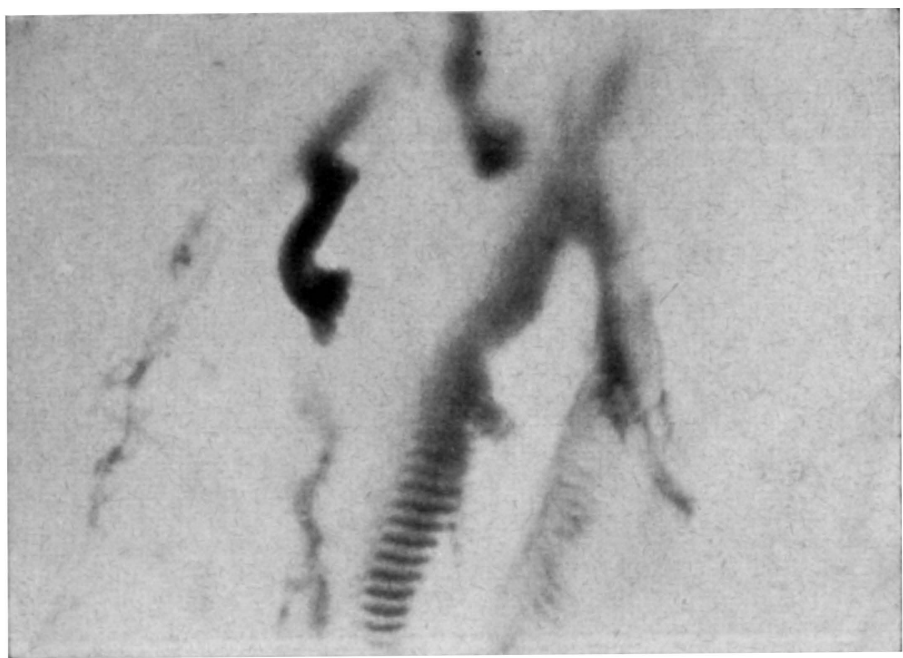

Fig. $\mathbf{7}$ - MIétodo de Boeke $(450 \times)$ : placa motora hipertrofiada.

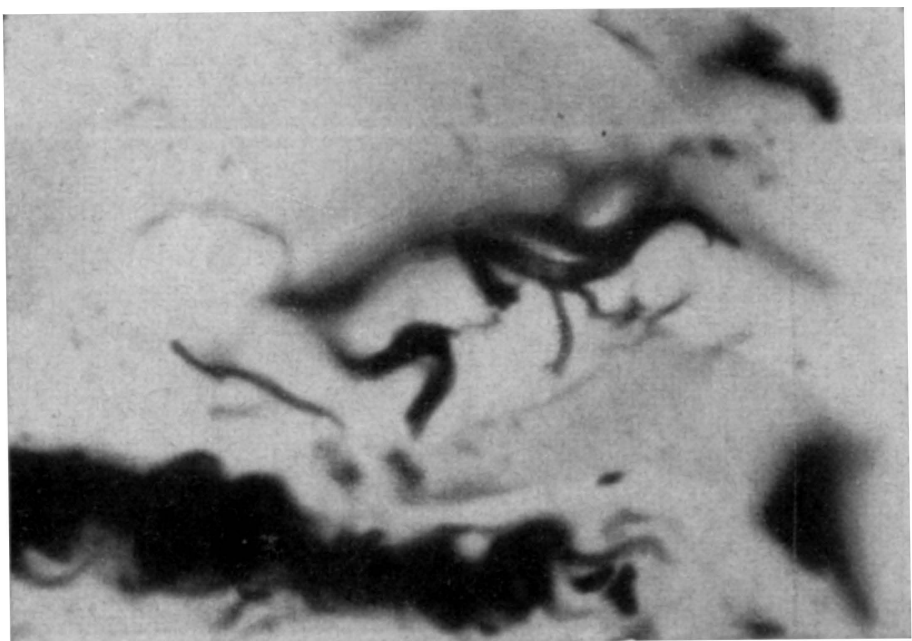

Fig. 8 - Método de Boeke $(450 \times)$ : placa motora hipertrofiada, intensamente impregnada e com pequenas ramificaçoes. 


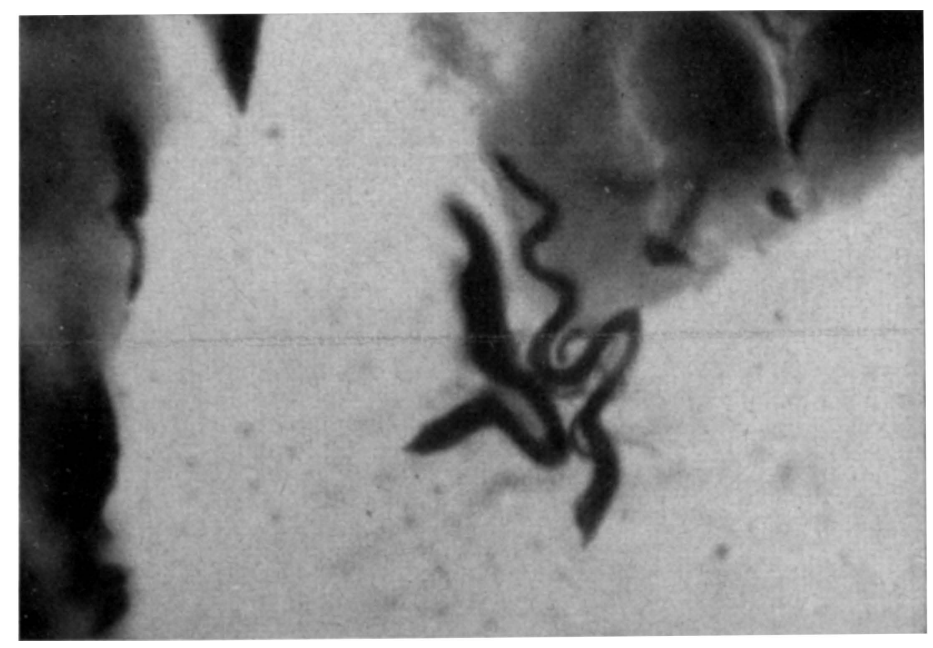

Fig. 9 - Método de Boeke (450×): placa motora hipertrofiada, intensamente impregnada, terminando-se por formaçāo em bola argêntica.

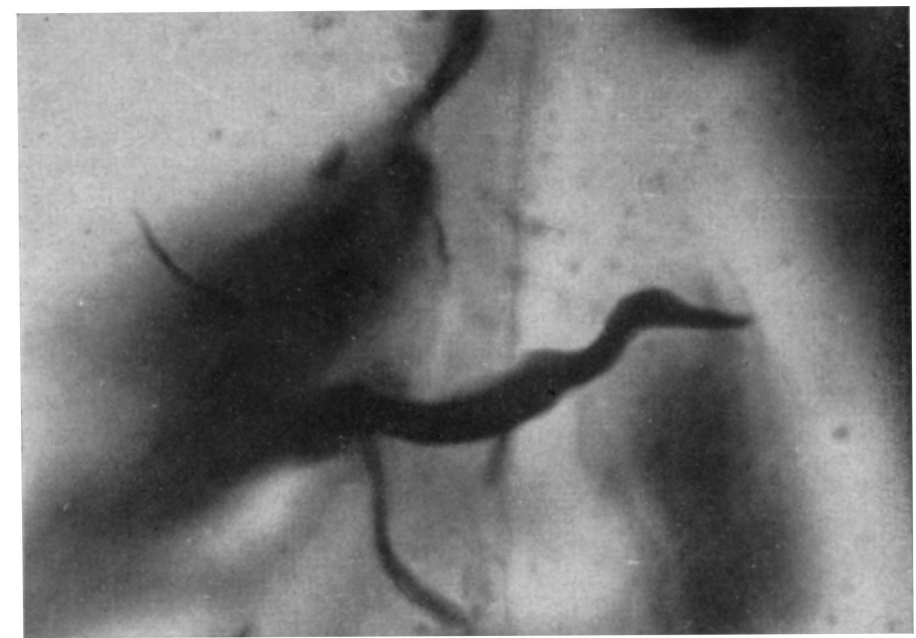

Fig. 10 - Método de Boeke $(450 \times)$ : terminação motora intensamente impregnada e hipertrofiada, que se termina por formacão em ponta de lança. 
que assume aspecto edemaciado (fig. 7); às vêzes as ramificações são tão intensamente impregnadas como o ramo principal (fig. 8). Estas alterações são visíveis também em plena fibra muscular, podendo-se notar nitidamente as estrias transversais desta última. Em um estágio mais avançado a placa motora desaparece, sendo substituida por formações semelhantes às bolas argênticas descritas por Lawrentjaw e Filatowa (fig. 9) ou por formaçōes em ponta de lança (fig. 10). O aspecto caracteristicamente patológico das alterações das terminações nervosas é constituído pelo neuroma de terminação. A placa motora, no início, apresenta finissimas ramificaçōes, sem que se possa afirmar que esta seja patológica, pois sòmente a existência de tais ramificações não autoriza afirmação segura. Se a irritação continuar, às ramificaçōes iniciais juntam-se novas colaterais cujo número aumenta paulatinamente; as colaterais se terminam, inicialmente, por formações em anéis ou aparelhos fibrilares transformando-se ulteriormente em pequenas massas argênticas. Finalmente, observamos a existência de engrossamentos na fibra principal e nas colaterais, formando-se o neuroma terminal. Estes três estágios são bem delimitados e perfeitamente observados, tendo sido estudados por Lawrentjew e Filatowa e por Guillén.

\section{COMENTARIOS}

A tuberculose laringea é, geralmente, secundária à pulmonar; a forma primitiva é tão rara que pràticamente carece de interêsse. Segundo Ulrici ${ }^{51}$ a tuberculose da laringe é diagnosticada clìnicamente em 10 a $30 \%$ e, anátomo-patològicamente, em 30 a $50 \%$ dos casos de tuberculose pulmonar; êste autor, em 1.700 casos de tuberculose pulmonar, encontrou lesões tuberculosas da laringe em 415, ou seja $24,4 \%$ e, em 1.020 autópsias de pacientes tuberculosos a complicação laringea foi verificada 477 vêzes ou seja $46,8 \%$, sendo mais freqüente nos homens que nas mulheres. Em nosso meio podemos considerar a incidência da complicação laríngea em níveis mais altos, como demonstrou Freitas 19 em estudo realizado em material semelhante ao nosso; em 320 autópsias de pacientes procedentes das mesmas enfermarias que os casos por nós utilizados, encontrou êste autor $60 \%$ de incidência de tuberculose da laringe. As alterações macroscópicas mais freqüentes são a infiltração e a ulceração, tendendo o processo a se propagar para a traquéia (Sticotti ${ }^{42}$ ); encontramos a infiltração mais freqüentemente que a ulceração.

As impregnações de laringes normais evidenciaram dois tipos de sinapse mioneural: a placa motora clássica e a terminação em retículo descrita primeiramente por Boeke ${ }^{2}$. A inervação da musculatura da laringe é feita por ambos aparelhos terminais, representando o segundo, provàvelmente, um degrau filogenèticamente superior. A existência da terminação em rêde descrita por Boeke, Stohr 43,44, 45,46,47 e, mais recentemente, por Feyrter ${ }^{17}$ e Jabonero ${ }^{28}$, leva a concluir que, no tipo de sinapse em plexo, as relações entre fibra nervosa e protoplasma celular são muito mais estreitas que na terminação livre. A aceitação da existência do retículo não nos força à aceitação da teoria exposta por Boeke ${ }^{3}$ para explicar sua significação e papel fisiológico. Em nossas impregnações de material normal, ob̉servamos ambos os tipos de terminaçōes. Sabemos da existência, no tecido conjuntivo, de várias formações terminais sensitivas de significação e papel fisio- 
lógico distintos. Acreditamos que não exista razão para admitir uma única maneira de terminação nervosa motora, com as provas morfológicas e fisiológicas que dispomos na atualidade; devemos aceitar ambos os tipos de terminações nervosas motoras, como aceitamos os vários tipos de terminaçōes sensitivas. Os anéis, botões e esférulas que constituem as terminações de muitas fibras pré-sinápticas representariam, ao ver de Jabonero, formas mais simples de terminaçōes sinápticas, um tipo de terminação correspondendo aos primeiros esboços da constituição das sinapses. A formação do retículo representaria um degrau mais elevado, um remate na organização entre as relações anatômicas e fisiológicas entre o pólo nervoso correspondente e o protoplasma dos elementos satélites intermediários, constituindo o "complexo neuroglial das sinapses" (Jabonero). A placa motora clássica é a mais singela e a terminação em plexo a mais complexa das formas de sinapse mioneural.

A neurofibrila começa a sofrer as conseqüências da lesão tissular antes mesmo da formação dos primeiros tubérculos. Segundo nossas observaçōes, é possivel que as lesões degenerativas tomem o caminho ascendente, sem que se deva excluir a possibilidade de lesōes nos gânglios produzindo alterações nas terminações, como foi descrito por Lawrentjew no gânglio cervical superior de pacientes tuberculosos. Que a tuberculose determina alterações nos neurônios dos gânglios simpáticos, nos é demonstrado pelos quadros histológicos de material obtido em pacientes com graves lesões pulmonares. Em 8 gânglios estrelados de pacientes que faleceram com grave acidente pulmonar no curso de tuberculose, pudemos verificar ${ }^{1 j}$ serem as alteraçōes essencialmente do tipo proliferativo, constituídas principalmente por hipertrofia e hiperplasia dos dendritos e formação de bolas argênticas que seriam conseqüentes à hiperfunção, por excitação do simpático; esta conclusão concorda com as opiniōes de Herzog ${ }^{22}$, Eissendecher ${ }^{10}$ e Emhart ${ }^{11}$ discutidas por nós em publicação anterior ${ }^{12}$. Nos casos de tuberculose não só os neurônios se encontram lesados; as fibras ganglionares também se alteram mostrando maior avidez pelos sais de prata, além de tortuosidades e nodosidades terminando, muita vez, por botōes patológicos que entram em contato com neurônios patológicos formando, com os dendritos dêstes, conexões grosseiras e fortemente impregnadas.

As neoformações em fibras terminais podem ser explicadas tendo em vista as modificaçōes regenerativas descritas por Cajal 6 nos nervos periféricos. Existe identidade entre o quadro histológico por nós observado nas terminações nervosas da laringite tuberculosa e no dos neuromas experimentais que tivemos oportunidade de estudar recentemente em material publicado por Dantas 9. Parece-nos de singular importância que fibras com brotamentos apareçam em zonas infiltradas particularmente por linfócitos. Muito embora pareça impróprio comparar a degeneração do neuroma do nervo seccionado experimentalmente com as imagens por nós encontradas nas lesōes tuberculosas onde atuam fatôres nocivos que não existem nos nervos seccionados, vale lembrar que, em certos casos, as fibrilas são parcialmente destruídas em um ponto de seu percurso, conservando a porção periférica 
vitalidade suficiente para esboçar regeneração. As fibras nervosas nas laringes com tuberculose evolutiva sofrem inflamação degenerativa inespecífica que, mesmo nas formas incipientes, è de suma importância, como acentua Guillén. Em paciente tuberculoso com laringe sem substrato patológico aparente, podemos encontrar lesões neurofibrilares que explicariam as manifestações dolorosas de que o paciente se queixava em vida. $\dot{E}$ de importância relacionar a neurite não só com o processo tuberculoso localizado na laringe, mais também com o sofrimento de todo o organismo. É evidente que na tuberculose avançada, quando se instala a afeção laríngea, ocorrem alterações metabólicas que determinam um estado carencial; nestas condições é difícil ou impossivel determinar qual a causa dos transtornos observados clìnicamente, não se sabendo se são as discretas alterações neurofibrilares ou se é carência metabólica que leva o tecido a uma distrofia favorecendo o desenvolvimento dos bacilos. Nos estados carenciais podem-se observar alterações degenerativas dos nervos; na pelagra Arteta ${ }^{1}$ descreveu alterações degenerativas segmentares com participação ativa das células de Schwann e alterações das terminações nervosas semelhantes às que encontramos em nosso material de laringite tuberculosa.

As alterações das placas motoras são de grande significação; nossos achados coincidem com os descritos por Lawrentjew e Filatowa e por Guillén. $O$ quadro histológico do neuroma de terminação concorda com as observações dos autores que estudaram o problema, levando a pensar na possibilidade de traduzirem o sofrimento dos neurônios antes das neurofibrilas apresentarem modificações morfológicas apreciáveis. Se esta interpretação fôr verdadeira, os neuromas terminais representam um indicador biológico de extraordinária sensibilidade, capaz de fornecer informações valiosas sôbre o estado funcional do soma neural, antes que possa ser evidenciada qualquer lesão anatômica do cilindro-eixo. Podemos comparar as alterações das terminações neuro-musculares na tuberculose com as lesões tróficas das fibras nervosas e também com as produzidas pelos̀ tóxicos. Em 1907 Tello ${ }^{50}$ estudou as modificações histológicas da sinapse mioneural e descreveu fenômenos degenerativos e regenerativos que aparecem após a secção do nervo, os primeiros constituidos pela hipertrofia das arborizações, pela fragmentação das neurofibrilas e pelo desaparecimento ulterior da placa motora. Porém nem tôdas as fibras degeneram com a mesma intensidade, fato êste já descrito por Cajal ${ }^{7}$. Em nossas preparações encontramos placas motoras com polimorfismo histológico, fato que atribuímos à maior ou menor injúria produzida pelo bacilo e à maior ou menor vulnerabilidade das fibras nervosas, concordando esta conclusão com as observações de Marinesco ${ }^{33}$. Isto concorda também com os trabalhos experimentais de Herrera ${ }^{21}$ que, intoxicando animais com o curare, encontrou modificações diversas na dependência da dose usada: se a dose era única e mortal, as lesões eram degenerativas e graves, porém se a dose era minima e repetida, as lesões passavam a ser proliferativas, tipicamente do tipo irritativo. Assim é que, na tuberculose, seriam explicadas as alterações, às vêzes degenerativas e outras vêzes proliferativas: as fibras nervosas mais resistentes e afastadas da lesão 
tuberculosa apresentariam alterações do tipo proliferativo, de caráter irritativo, enquanto que as mais vulneráveis situadas nas vizinhanças da lesão apresentariam alterações do tipo degenerativo. $\mathrm{Na}$ proporção que evolve $\mathrm{o}$ processo tuberculoso, as alterações proliferativas aumentam para depois assumirem aspecto de degeneração.

Jabonero ${ }^{24}$, estudando as fibras nervosas no esôfago, em 3 casos de tuberculose, descreveu engrossamentos irregulares ao longo de seu trajeto e afirmou que as alterações se iniciavam ao nivel das terminações e suas arborizações. Êste tipo de alteração corresponde às lesões proliferativas descritas por Lawrentjew e Filatowa, por Guillén e às que aqui descrevemos; elas não são específicas já que se parecem muito com as que observamos nos neuromas experimentais e são idênticas às descritas por Ferrer e Ribas ${ }^{16}$ nas vizinhanças das lesões leprosas. Lowell, Puchol e Perez ${ }^{32}$ descreveram, também na lepra, lesões de fibras nervosas representadas por engrossamentos e nódulos; em outras fibras que não apresentavam tais modificações, observaram profundas alterações nos axônios que apareciam fragmentados, com trajeto em espiral, tortuosos e com freqüentes figuras em rosário; em todos os casos existiam evidentes lesões nos nervos e aparelhos terminais - do tipo de neurite histològicamente inespecifica, com degeneração dos axônios - semelhantes às observadas em nossos casos de laringite tuberculosa. Jabonero descreve, em uma fibra, formação fusiforme com aparente aumento de neuroplasma e adelgaçamento das neurofibrilas; figura semelhante tivemos oportunidade de observar em nossos casos e concordamos com êste autor quando diz ser esta formação de caráter patológico e não devida a alteração pós-mortal como querem Herzog ${ }^{22}$ e Herzog e Martinez ${ }^{23}$.

Muitas vêzes as fibras apresentam alterações proliferativas sem que se possa observar lesões tuberculosas em áreas circunvizinhas; êste fato terá sua explicação se aceitarmos não ser o processo local a causa das alterações dos elementos nervosos. Os neurônios de tamanho e tipo semelhantes se reunem no gânglio em grupos isodinâmicos ${ }^{13}$; em várias oportunidades ${ }^{12,14}$ podemos verificar que as lesões histológicas se apresentam preferentemente localizadas nos neurônios que formam tais grupos. Lesões localizadas nas terminações progridem por via ascendente determinando alteração grave nos neurônios; como os elementos de um grupo enviam seus prolongamentos para determinado ponto formando o ninho dendrítico, a disfunção de certo número de neurônios determinaria a disfunção de todo o grupo, traduzindo-se, nas terminações periféricas dos neurônios secundàriamente atingidos, por alterações de tipo proliferativo. Estas conclusões concordam com as observações de Lawrentjew e Filatowa que descreveram, nos músculos da laringe de pacientes tuberculosos porém absolutamente livres de lesões específicas, alterações do tipo proliferativo; para êstes autores o processo tuberculoso provoca degeneração em todio o sistema do nervo vago e tais lesões ocorreriam em regiões não diretamente acometidas pelo bacilo de Koch. Os produtos das lesões tuberculosas têm, como tôdas as substâncias protéicas, neurotropismo positivo, com a propriedade de circular nas bainhas nervosas, 
principalmente na de Mauthner, seguindo a via ascendente; assim, sendo as terminações vegetativas e motoras lesadas pelo processo tuberculoso, os produtos tóxicos se difundem até os neurônios de origem. Por êste mecanismo seria sèriamente afetado todo o sistema neurovegetativo regional.

$\mathrm{Na}$ infecção tuberculosa o terreno tem suma importância e está subordinado diretamente ao sistema neurovegetativo. O conceito de terreno deve ser lembrado em se tratando de tuberculose e explica muitos pontos obscuros, pois, se em um tuberculoso que elimina durante anos material altamente contaminado sem que sua laringe apresente modificações apreciáveis, por que em determinado momento ela há de se contaminar? Outra explicação não cabe senão a de que o bacilo desempenha papel secundário, sendo a causa principal o terreno modificado pelo sistema nervoso vegetativo. Na tuberculose temos, em suma, dois fatôres antagônicos - o bacilo e o terreno - cuja luta se estabelece em pleno tecido conjuntivo.

Sendo o tubérculo formação essencialmente conjuntiva, nada autoriza afirmar que na sua gênese influam sòmente elementos celulares, já que os fenômenos vasculares, como em tôda a inflamação, têm papel relevante. O endotélio vascular possui propriedades definidas e a dilatação capilar é ativa, desempenhando a inervação vegetativa papel preponderante (Kuntz ${ }^{30}$ ) nos fenômenos defensivos; as terminações vegetativas nos pequenos vasos estão constituídas por um sincício nervoso (Jabonero ${ }^{26}$ ) ou por um plexo terminal que inerva a musculatura lisa (Bullón ${ }^{4}$ ). Assim é que não existe razão para excluir as fibras vegetativas e considerar o tubérculo como sendo a resultante de uma ação na qual as fibras e os neurônios não tomam parte. Em outras palavras, o aparecimento de lesões da laringe, como complicação da tuberculose pulmonar evolutiva, não pode ser devido ao simples contato prolongado da mucosa com material fortemente bacilifero, pois uma mucosa indene suporta, sem apresentar modificações, a passagem de escarro rico em bacilo, o mesmo não acontecendo com uma mucosa que apresenta transtornos circulatórios, embora aparentemente indene, ou com alterações nervosas; o alojamento do bacilo da tuberculose requer a pré-existência de terreno apropriado. Encontramos, na laringe, elementos de estrutura, significação e gênese distintas - cartilagem, músculo, glândula, epitélio e tecido conjuntivo - onde se aninham vasos e especialmente nervos que não se restringem apenas a conduzir estímulos da vida de relação; a êles é devida a regulação da vida vegetativa de cada elemento e suas reações defensivas. O foco tuberculoso é o ponto de partida de estímulos que regulam todo o mecanismo da alergia. Na tuberculose Moro e Keller ${ }^{35}$ assinalaram a existência de reações vegetativas anormais e Seiffert to $^{\circ}$ afirmou que a reação antígeno-anticorpo reforçaria a sensibilidade local por estímulos dos centros vegetativos. A alergia tuberculosa seria, para Seiffert, fenômeno essencialmente nervoso. Rosenthal valorizou o papel do sistema vegetativo na tuberculose e afirmou que o bacilo só pode se desenvolver naqueles pontos em que exista disfunção vegetativa.

As correlações entre o sistema vegetativo e as reações orgânicas à tuberculose têm papel relevante no mecanismo patogênico das formas parti- 
culares da doença (Sturm), como no caso da laringite. Da incorporação da patologia neural às investigações sôbre a tuberculose, limitadas até a pouco ao problema da patologia celular, cabe esperar uma diretriz no modo de analisar os problemas da doença tuberculosa; isto só será proveitoso se não nos limitarmos às vagas abstraçōes de alergia, bacilo e órgão e pensarmos no organismo como um todo regulado pelos sistemas nervoso e endócrino. Se para o processo alérgico fôr aceita uma direção central e encefálica (Sturm), a incorporação do conceito de alergia na doutrina da tuberculose perde posição em favor do reconhecimento de um preponderante fator nervoso na sua patogenia. Michejew e Pawliutschenko ${ }^{34}$, em 18 casos de tuberculose crônica, encontraram no centro vegetativo encefálico, graves alterações (vacuolização, picnose, destruição celular, proliferação e polimorfismo da glia, alterações vasculares). A tuberculose determina alteração vegetativa por ação microbiana nas terminações nervosas, por provocação de processos inflamatórios nos centros nervosos e por ação nas glândulas de secreção encarregadas de regular o tono vegetativo (Bufano ${ }^{5}$ ). Com Speransky sabemos que o sistema nervoso não só está interessado nos processos patológicos, senão que, freqüentemente, os provoca, estando a capacidade de reagir de um tecido frente à infecçăo tuberculosa na dependência direta da função do segmento nervoso correspondente. Speransky observou que a secção unilateral do vago imprime à infecção tuberculosa do pulmão homolateral um caráter mais benigno que a produzida em um animal inervado normalmente e que a secção subdiafragmática do vago torna muito menos intensa a reação dos órgãos abdominais à infecção tuberculosa que nos animais testemunhas.

Ao se iniciar a necrose, as fibras nervosas contidas no tecido são lesadas e como são continuação do soma celular, qualquer causa que atue sôbre elas repercute na célula nervosa. Se a alteração da fibra é mínima, a lesão celular será diminuta e no caso de restitutio ad integrum o episódio carecerá de significação. A lesão celular sendo grave, reflete-se à distância, na terminação do axônio, resultando distrofias tissulares que predispõem o organismo a processos graves que tendem à cronicidade adquirindo características especiais. Neste caso, quando aparece alguma solução de continuidade no revestimento mucoso da laringe, os tecidos subjacentes têm que se haver com condições completamente desconhecidas; as injurias agem diretamente sôbre os tecidos e tais estímulos são levados até os neurônios que reagem na razão direta de sua intensidade e persistência. Sendo a injúria suficientemente poderosa para exaurir completamente a capacidade funcional do neurônio, a distrofia aparece no local de menor resistência e a lesão tende a crescer. Tôda a vez que as terminações nervosas sofrem lise, a alteração deixa de ser local para ser geral, passa a afetar os prolongamentos dos neurônios de tôda a cadeia, adquirindo características essencialmente patológicas. Devido a estas alterações, o conectivo-vascular do mesênquima, encarregado da defesa local, claudica por terem os mecanismos vasomotores perdido sua labilidade funcional já que as terminações nervosas e os neurônios ganglionares sofreram lesões irreversiveis. 
$\mathrm{Na}$ tuberculose laríngea produtiva, de evolução lenta, as terminações nervosas apresentam alteraçōes de caráter proliferativo - nodosidades, engrossamentos, brotamentos fibrilares — e se encontram infiltradas por elementos linfocitários; o gânglio cervical superior aparece também infiltrado e com alterações essencialmente proliferativas. $\mathrm{Na}$ agressão bacilar violenta, que determina em pouco tempo a lise das terminações, os neurônios do nervo vago e do nervo cervical superior apresentam aspecto edematoso, com perda da estrutura nuclear, com fragmentação dos prolongamentos, com nodosidades, com hiperplasia e hipertrofia dos dendritos.

\section{RESUMO E CONCLUSOES}

Foram estudadas as laringes de 16 pacientes que faleceram no curso de tuberculose pulmonar grave e as de 4 indivíduos normais. As impregnações foram feitas pelo método de Boeke e, eventualmente, pelo nitrato de prata reduzido de Cajal, utilizando-se também as colorações pela hematoxilina-eosina e pelo Gomori. Nas laringes normais foram estudadas as terminações nervosas, sendo descritas e discutidas as terminações livres e em plexo, concluindo-se serem as segundas filogenèticamente superiores, permitindo maiores relaçōes entre a fibra nervosa e o protoplasma celular. Nos casos patológicos as impregnações mostraram alterações nas terminações e nas fibras nervosas. Nas terminações ocorreu hipertrofia com formação de bolas argênticas e hiperplasia representada pelo aparecimento de brotamentos e colaterais que constituem o neuroma da terminação. As fibras nervosas apresentam-se edemaciadas, com nodosidades, alterações neurofibrilares e perda de apetência pelos sais de prata, estando mais sèriamente lesadas nas vizinhanças de áreas tuberculosas. $\mathrm{Na}$ tuberculosa laringea de evolver lento, as terminações e fibras nervosas apresentam, predominantemente, alterações de caráter proliferativo. Na tuberculose de evolução rápida, as fibras nervosas evidenciam maior número de alterações degenerativas e as terminações nervosas entram em lise. As alterações não são específicas já que podem ser observadas em outras entidades.

\section{SUMMARY AND CONCLUSIONS}

\section{Histopathology of the nerve endings in the tuberculous laryngitis.}

The larynges of 16 patients who died in the course of severe pulmonary tuberculosis and of 4 normal subjects are studied. Impregnations were done by Boeke's method and sometimes by Cajal's reduced silver nitrate; stainings by hematoxylin-eosine and Gomori were also used. In the normal larynges the nerve endings were studied; free and plexual nerve endings were described and discussed; the author states that this latter pattern is of higher phylogenetical rank and allows better relationship between the nerve fiber and the protoplasm. In the pathological cases the stainings showed changes in the nerve endings and fibers; in the nerve endings hy- 
pertrophy with development of argentic balls and hyperplasia (buds and collaterals of the ending neuroma) are seen; nerve fibers are swollen, with nodosities, changes in the neurofibrils and loss of affinity for the silver salts; the lesions are more severe in the neighborhood of the tuberculous processes. When the laryngeal tuberculosis develops slowly, proliferative changes prevail in the nerve endings and fibers; when the evolution is rapid, the nerve fibers show a greater number of degenerative changes and the nerve endings go into lysis. The changes are not specific, as they can be detected in other diseases.

\section{REFERENCIAS}

1. ARteta, J. L. - Anatomia patológica e histopatoiogía de la llamada glositis pelagrosa. Trab. Inst. Cajal Inv. Biol., 34:65-136, 1942. 2. BOEKE, J. - Die motorische Endplatte bei den hoheren Vertebraten, ihre Entwickelung, Form und $\mathrm{Zu}$ sammenhang mit der Muskelfaser. Anat. Anz., 35:193-226, 1909. 3. BOEKE, J. Sympathetic endformation, its synaptology, interstitial cells, periterminal network, and its bearing on neurone theory. Discussion and critique. Acta Anat., 8:18-61, 1949. 4. BULLON-RAMIREZ, A. - Experimentelle Studien über die Innervation der kleinen Blutgefässe. Acta Neuroveget., 14:133-147, 1956. 5. BUFANO, M, - La Patologia e la Clinica del Sistema Nervoso Vegetativo. Società Editrice Libraria, Milano, 1940. 6. CAJAL, S. R. - Mechanisme de la régénerescence des nerfs. Trav. Lab. Recher. Biolog. Univ. Madrid, 4:123-218, 1905. 7. CAJAL, S. R. - Degeneration and Regeneration of the Nervous System. Trad. inglêsa de R. M. May. Oxford Univ. Press, Londres, 1928. 8. CAJAL, S. R.; CASTRO, F. de - Elementos de Técnica Micrográfica del Sistema Nervioso. Tip. Artistica, Madrid, págs. 192 e 193. 9. DANTAS, R. T. - Dos neuromas de amputação: contribuição experimental para sua prevenção. Publicaçōes da Univ. da Bahia (Brasil), VII-3, 1958. 10. EISENDECHER, C. M. - Relaciones anátomo-patológicas entre la arterioesclerosis aórtica e los ganglios simpáticos. Bol. Soc. Biol. de Concepción (Chile), 11:45-65, 1937.11. EMHART, O. - Participación de los ganglios nodoso y yugular del vago y de sus núcleos centrales en la tuberculosis pulmonar-laringea e en la úlcera gástrica. Bol. Soc. Biol. de Concepción (Chile), 16:45-58, 1942. 12. FERNANDEZ, J. - Morfopatologia de los ganglios simpáticos lombares. Tesis doctoral, Madrid, 1954. 13. FERNANDEZ, J. - Contribuição ao estudo da histologia normal do sistema nervoso periférico. Tese de doutoramento. S. Artes Gráficas, Salvador (Bahia), 1955.14. FERNANDEZ, J. - Morfopatologla dos gânglios simpáticos lombares na tromboangefte obliterante. Rev. da Ass. Méd. Brasil., 2:237-242, 1956. 15. FERNANDEZ, J. - Histopatologia do gânglio estrelado na tuberculose pulmonar. Arq. Neuro-Psiquiat., 15:1-14, 1957. 16. FERRER e RIVAS - Cit. por Jabonero ${ }^{24}$. 17. FEYRTER, F. - Uber die Pathologie der Vegetativen Nervosen Peripherie und ihrer Ganglionaren Regulatiosstatten. Verlag Wilhelm Maudrich, Wien, 1951. 18. FILATOWA, A. G.; LAWRENTJEW, B. J. - Uber die pathologische Histologie der Nerven und Ganglien bei Kehl und Lungentuberkulose. Virchow Archiv., 286:1-10, 1932.19. FREITAS, U. - Anátomo-patologia da tuberculose do laringe. Tese. Era Nova Ltda., Bahia, 1945. 20. GUILLEN, M. F. - Lesiones nerviosas en la laringe tuberculosa: posible papel patogénico. Trab. Inst. Cajal Inv. Biol., 43:85-144, 1951. 21. HERRERA, J. M. - Les lésions de la plaque motrice dans l'intoxication par le curare. Trav. Lab. Recherc. Biolog. Univ. Madrid, 31:1-19, 1936-37. 22. HERZOG, E. - Histología patológica del sistema nervioso vegetativo. In L. B. Muller, Sistema Nervioso Vegetativo, Ed. Labor, Madrid, 1937, págs. 894-970. 23. HERZOG, E.; MARTINEZ, A. - Alteraciones patológicas de los ganglios vegetativos intra y extracardiacos. Rev. Sudam. Morfolog., 2:1-22, 1944. 24. JABONERO, V. - Estudios sobre la histopatología del sistema neurovegetativo periferico. Arch. Méd. Experiment., 14:31-58, 1951. 25. JABONERO, V. — Les fuseaux neuro-leio-musculaires des 
voies respiratoires et leurs altérations au cours de la tuberculose. Pract. Oto-rhinolaryngol., 14:38-46, 1952. 26. JABONERO, V. - Efferente Innervation der Blutgefässe. Acta neuroveget., 14:16-26, 1956. 27. JABONERO, V. - Comunicação pessoal. 28. JABONERO, V.; GOMEZ, B.; BORDALLO, F.; PEREZ-CASAS, J. - Organización anatomica del sistema neurovegetativo periferico. Instituto Nacional de Ciencias Médicas, Madrid, 1951. 29. JOFFrOY - Cit. por Guillén ${ }^{18}$. 30. KUNTZ, A. - The Autonomic Nervous System. Lea \& Febiger, Filadélfia, 1953. 31. LAWRENTJEW, B. J.; FILATOWA, A. C. - Histopathologie du nerf laryngé inférieur et de ses terminaisons au cours de la laryngite tuberculeuse. Trav. Lab. Recher. Biolog. Univ. Madrid, 29:319-338, 1934. 32. LOWELL, L.; PUCHOL, J. R.; PEREZ, A. P. - Aportación al conocimiento histopatológico del sistema nervioso periferico en la lepra. Ann. V Cong. Intern. de la Lepra, Havana, 1948, págs. 1213-1221. 33. MARINESCO, G. - La Cellule Nerveuse. Tome II, chap. XXI. Octave Doin et Fils, Paris, 1909. 34. MICHEJEW, W. W.; PAWLJUTSCHENKO, E. M. - Tuberkulose und das vegetative Nervensystem: zur pathologischen Anatomie der vegetativen Zentren bei chronischer Tuberkulose. Arch. f. Psychiat. und Nervenkrank., 84:227-250, 1928. 35. MORO, E.; KELLER, W. - Tuberkulose Hautallergie nach intrakutaner stimulatimpfung von Tuberkulin und Kuhpockenlymphe. Dtsch. Med. Wochr., 51:1015-1017, 1925. 36. ROSENTHAL, G. - Le système sympathique et la tuberculose pulmonaire. Arch. Méd.-Chir. de l'App. Respir., 12:215-233, 1937. 37. ROSENTHAL, G. - Le sympathique des tuberculeux. Clinique (Paris), 32:207-210, 1937. 38. ROSENTHAL, G. - Nouveaux documents pour l'étude de la sympathologie dans la tuberculose pulmonaire. Clinique (Paris), 34:3-6, 1939. 39. ROSENTHAL, G. - Documentation et interprétation du rôle du système sympathique dans la tuberculose pulmonaire. Rev. Gén. de Clin. et Thérap., 53:437-440, 1939. 40. SEIFFERT, W. Resistenz und Allergie gegen Tuberkulose. Klin. Wchnschr., 17:721 e 761, 1938. 41. SPERANSKY, A. D. - Bases para una Nueva Teoria de la Medicina. Ed. Psique, Buenos Aires, 1954. 42. STICOTTI, S. - Le alterazioni anatomo-istologiche della trachea in corso di tuberculosi polmonare cronica. Arch. de Vecchi, 2:227-255, 1939. 43. STOHR, Ph. Jr. - Mikroskopische Stuđien zur Innervation des Magen-Darmkanales. Ztschr. Zellforsch. u. Mikr. Anat., 12:66-154, 1931. 44. STOHR, Ph. Jr. Mikroskopische Studien zur Innervation des Magen-Darmkanales. Ztschr. Zellforsch. u. Mikr. Anat., 16:123-197, 1932. 45. STOHR, Ph. Jr. — Mikroskopische Studien zur Innervation des Magen-Darmkanales. Ztschr. Zellforsch. u. Mikr. Anat., 21:243-278, 1934. 46. STOHR, Ph. Jr. - Beobachtungen und Bemerkungen über die Endausbreitung des Vegetativen Nervensystems. Ztsch. Anat. u. Entwcklngsgesch., 104:133158, 1935. 47. STOHR, Ph. Jr. - Embriologia e histologia general de las partes periféricas del sistema nervioso de la vida vegetativa. In L. B. Muller: Sistema Nervioso Vegetativo. Ed. Labor, Madrid, 1937, págs. 24-52. 48. STURM, A. - Grundbegriffe der Inneren Medizin. Gustav Fischer Verlag, Stuttgart, 1955. 49. STURM, A. - Patología Clínica del Pulmón en Relación con el Sistema Nervioso Vegetativo. José Janés Editor, Barcelona, 1955. 50. TELLO, J. F. - Dégénération et régénération des plaques motrices après la section des nerfs. Trav. Lab. Recherc. Biolog. Univ. Madrid, 4:117-149, 1907. 51. URICI, H. - Diagnóstico y Tratamiento de la Tuberculosis Pulmonar y Laringea. Editorial Labor, Barcelona, 1935.

Rua Prof. Viegas, 66, apt॰ $601-$ Cidade do Salvador (Bahia), Brasil. 